\title{
HISTORIA
}

\section{MEMÓRIA DE EGRESSOS DA ESCOLA DE ENFERMAGEM DA UINIVERSIDADE DE SÃO PAULO}

\section{Natália Fialho Mota', Genival Fernandes de Freitas², Amanda Loos Agra1, Juliana Moreira Lino Viana', Magali Hiromi Takashi', Taka Oguisso ${ }^{3}$}

'Enfermeiras graduadas da Escola de Enfermagem da Universidade de São Paulo.

${ }^{2}$ Professor Doutor do Departamento de Orientação Profissional da Escola de Enfermagem da Universidade de São Paulo.

${ }^{3}$ Professora Titular do Departamento de Orientação Profissional da Escola de Enfermagem da Universidade de São Paulo.

* Trabalho de Iniciação Científica desenvolvido pelos autores com financiamento da Fundação de Amparo à Pesquisa do Estado de São Paulo

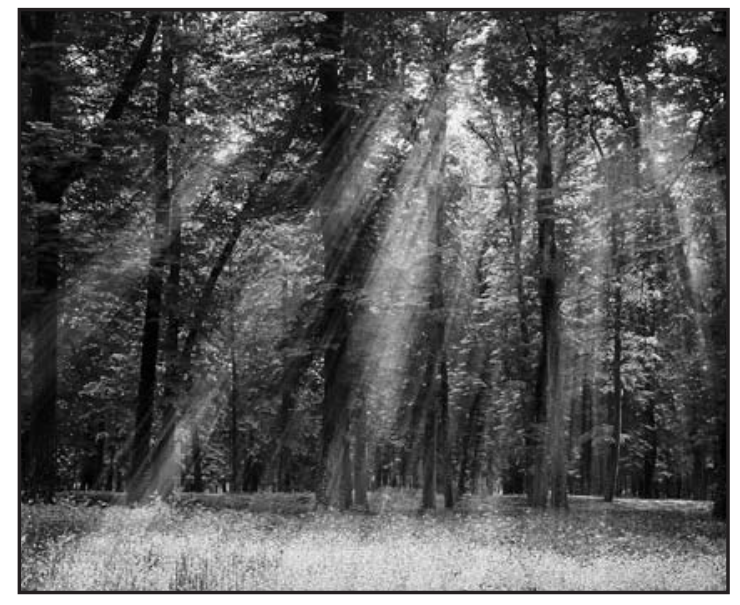

MEMORY OF GRADUATES OF THE SCHOOL OF NURSING, UNIVERSITY OF SÃO PAULO

\section{ABSTRACT}

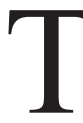
his is a study of social-historical approach, contributing to the recovery of memory and identity of the profession of nursing. The objectives of this study were to identify the situations of facilities and/or difficulties towards professional development during the undergraduate course and after insertion in the labor market by alumni EEUSP formed in the de1980/1981. We used the Oral History of Life for data collection and technique of Bardin technique for interpretation and analysis of findings. Seventeen graduated nurses were interviewed: some subjects revealed facilities for professional practice as to have more than a job, autonomy and actuation in different areas of knowledge and of practice. Other research collaborators considered that the difficulties they experienced were related to working conditions, remuneration, working hours, among others aspects. The study provided the continuity of the pioneering work started in the 1970 s, in that school, were identified in which the graduates in the period 1946 to 1979 , contributing to the recovery of historical memory of nursing.

Key words: Nursing, History of Nursing, Memory.

MEMORIA DE LOS GRADUADOS DE LA ESCUELA DE ENFERMERÍA DE LA UNIVERSIDAD DE SÃO PAULO

\section{RESUMEN}

7 ste es un estudio de abordaje históricosocial, contribuyendo a la recuperación de la memoria y la identidad de la profesión de 
enfermería. Los objetivos de este estudio fueron identificar las situaciones de facilidades y/o dificultades hacia el desarrollo profesional en el curso de pregrado y después de la inserción en el mercado laboral de ex alumnos formados en la EEUSP de 1980 a 1981. Se utilizó la historia oral de vida como técnica de recolección de datos y la técnica de Bardin para la interpretación y el análisis de los resultados. Diecisiete enfermeros licenciados fueron entrevistados: algunos revelaron facilidades para el desarrollo de la práctica profesional tales como la posibilidad de más de un vínculo de trabajo, la autonomía y el hecho de poder actuar en diversas áreas del conocimiento y de la práctica. Otros participantes consideraron que las dificultades se refieren a las condiciones de trabajo, remuneración, horas de trabajo, entre otros aspectos. El estudio posibilitó la continuidad de la labor pionera que se inició en la década de 1970, en esa escuela, en que se identificaron los graduados en el período 1946 a 1979, contribuyendo a la recuperación de la memoria histórica de la enfermería.

Palabras clave: Enfermería, Historia de la Enfermería, Memoria.

\section{RESUMO}

7 rata-se de um estudo de abordagem histórico-social, contribuindo para o resgate da memória e da identidade da profissão da enfermagem. Os objetivos deste estudo consistem em identificar as situações de dificuldades e/ou facilidades frente ao desenvolvimento profissional durante o curso de graduação e após a inserção no mercado de trabalho por ex-alunos da EEUSP, formados nos anos de 1980/1981. Utilizou-se a História Oral de Vida como técnica para a coleta de dados do universo pesquisado e a técnica de Bardin para interpretação e análise dos achados. Foram entrevistados dezessete ex-alunos: alguns colaboradores pontuaram facilidades para o exercício profissional como possibilidade de mais de um vínculo empregatício, autonomia e o fato de poder atuar em várias áreas do conhecimento e da práxis. Outros colaboradores consideraram que as dificuldades existentes referiam-se às condições de trabalho, remuneração, jornada, dentre outros aspec- tos. O estudo propiciou a continuidade do trabalho iniciado na década de 1970, na referida escola, no qual foram identificados os alunos formados no período de 1946-1979, contribuindo para o resgate histórico da memória da enfermagem.

Palavras chave: Enfermagem, História da Enfermagem, Memória.

\section{INTRODUÇÃO}

Estudos têm ressaltado a importância de acervos históricos para a memória da enfermagem, o que contribui para a consciência política e a formação dos futuros enfermeiros. Por exemplo, sabe-se que o Arquivo Histórico da Escola de Enfermagem Anna Nery (EEAN/UFRJ) - seu Centro de Documentação (CD) formou-se de maneira espontânea, em razão das atividades administrativas e pedagógicas da instituição. O Arquivo detém um rico e significativo patrimônio em documentos preservados. Esses documentos são cartas, relatórios, comunicações, históricos acadêmicos, livros de atas, fotografias e outros registros, que pertencem à História da Escola, desde sua criação até os dias atuais (SAUTHIER, CARVALHO, 1999).

Ao discorrerem sobre a organização do Centro de Documentação da EEAN/UFRJ (CD/EEAN), alguns autores observaram o valor da preservação documental e dos registros históricos (SAUTHIER, BARREIRA, 1999). Nessa perspectiva, percebe-se a importância dos documentos históricos, imagens e registros, os quais podem ajudar na recuperação da memória de uma instituição, profissão ou sociedade, considerando-se o fato de que os documentos servem como fontes de informações para profissionais de diversas áreas do conhecimento humano. Daí a importância acerca do valor dos documentos para a formação de uma consciência social sobre a significação e a utilidade de acervos documentais e necessidade de sua preservação e disponibilização para o público, em geral.

A Escola de Enfermagem da Universidade de São Paulo (EEUSP), criada pelo Decreto-Lei n. ${ }^{\circ}$ 13.040, de 31 de outubro de 1942, prepara enfermeiros, docentes, pesquisadores e especialistas em todos os ramos da Enfermagem, promovendo a 
realização de estudo, pesquisas e cursos para o aperfeiçoamento do ensino e do exercício da Enfermagem e da Obstetrícia, prestando serviços à comunidade em cooperação com os poderes públicos e entidades particulares, visando a melhoria das condições de saúde da população e o desenvolvimento da Enfermagem no âmbito local, nacional e internacional.

O curso de graduação recebe anualmente cerca de 80 alunos selecionados por meio de um concurso vestibular, e tem por finalidade formar bacharéis em enfermagem e enfermeiros licenciados para atividades docentes em nível profissionalizante. Cabe pontuar que a partir do ano de 2005, extinguiu-se a especialização em enfermagem obstétrica na EEUSP, dada a criação de um curso específico de obstetrícia no campus da USP Leste.

Em 20 de outubro de 1992, quando a EEUSP estava prestes a celebrar seu cinquentenário, foi inaugurado o Centro Histórico-Cultural da Enfermagem Ibero-Americana - CHCEIA com a perspectiva de centralização do acervo de obras literárias, artes, objetos e documentos que retratassem a evolução da enfermagem a partir de um recorte histórico, qual seja, 1942 ou o ano de fundação da Escola. A proposta fundamental, segundo a então diretora da EEUSP, Dra. Tamara Iwanow Cianciarullo, era "reavaliar o passado para visualizar o futuro", para divulgar trabalhos da Enfermagem, preservar seu patrimônio histórico e abrir novos caminhos para futuras pesquisas.

À época da sua fundação, o CHCEIA tinha entre seus objetivos: constituir-se em um centro de referência de pesquisa histórica da Enfermagem Brasileira e Ibero-Americana; recolher, armazenar e preservar obras literárias, artísticas, objetos e documentos históricos da Enfermagem em nível nacional e internacional; desenvolver atividades de educação extensiva à comunidade, abrangendo escolas de $1 .^{\circ}, 2 .^{\circ}$ e $3 .^{\circ}$ graus, o público em geral, e mais especificamente estudantes, docentes e profissionais da área; estabelecer uma política cultural vinculada à recuperação da memória da Enfermagem, com apresentação de material e equipamentos, fotografias e outros objetos dentro de um programa visual em exposições fixas e itinerantes e promover intercâmbio entre comunidades e instituições nacionais e internacionais.
A referida Escola tem como meta a geração de novos conhecimentos e sua aplicação nas práticas assistencial e gerencial do enfermeiro, contribuindo para um processo de educação permanente dos profissionais de enfermagem. Assim, a realização deste estudo de natureza histórico-social tem como interesse principal a preservação da memória da Enfermagem e, particularmente, da Escola de Enfermagem da USP, enquanto instituição formadora de gerações de enfermeiros. O estudo em pauta se organiza, buscando recuperar a trajetória dos egressos da EEUSP, sua formação acadêmica, oportunidades profissionais e pessoais, assim como fatos importantes que marcaram sua vida.

Cabe ressaltar que a enfermagem como prática social, desde sua origem, constituiu-se em uma das principais metas no processo de profissionalização da carreira, priorizando-se a formação e qualificação de recursos humanos em Enfermagem, contribuindo para o reconhecimento social, valorização da profissão, mormente pela construção dos saberes específicos da Enfermagem enquanto profissão com um caráter liberal (OGUISSO, 2007).

Em 2005, vários discentes interessaram-se em participar da confecção de projetos de pesquisa articulados ao projeto temático intitulado "O desenvolvimento histórico social da profissão de Enfermagem", em desenvolvimento pelo Grupo de Pesquisa História e Legislação da Enfermagem, da Escola de Enfermagem da Universidade de São Paulo (EEUSP).

A presente investigação teve como objetivos: Identificar e analisar os fatores que propiciaram a escolha e o exercício profissional, as dificuldades enfrentadas durante a atuação profissional por exalunos egressos da EEUSP no período de 1980-81.

Cabe pontuar que a escolha do tema e o período estudado justificam-se pelo fato de, no final dos anos 1970, Amália Corrêa de Carvalho ter dado início ao levantamento dos egressos da EEUSP da primeira turma de 1946 até o ano de 1973 (CARVALHO, 1980).

\section{Aspectos Metodológicos e Éticos}

A população foi constituída por ex-alunos formados na Escola de Enfermagem da USP, no período de 1980 a 1981. Do universo pesquisado, foram sorteados, de forma aleatória, dez por cento 


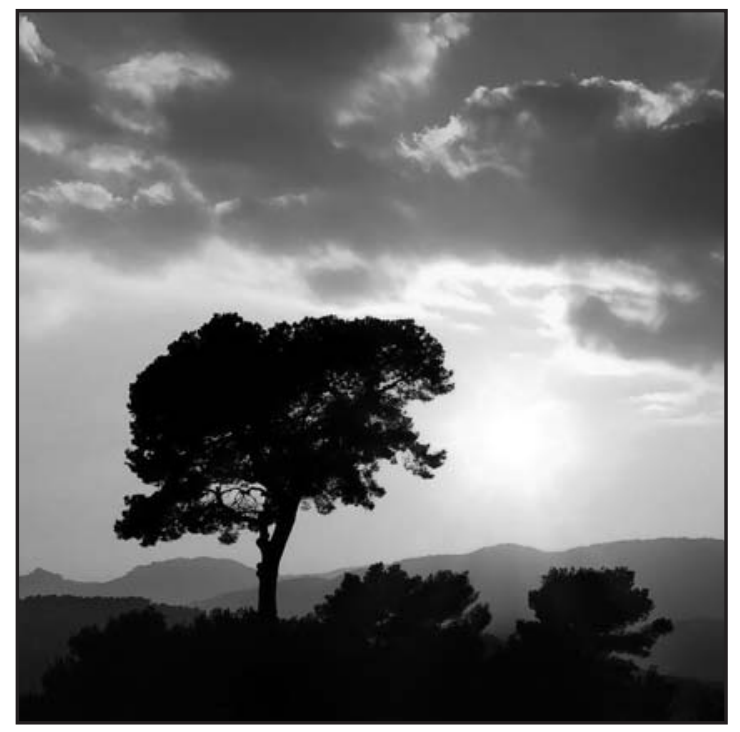

da população, de acordo com os seguintes critérios de inclusão: terem se formado nessa Escola no período de 1980 a 1981 e aceitarem participar de forma livre e espontânea do estudo proposto.

$\mathrm{O}$ projeto de pesquisa foi submetido à apreciação da Comissão de Ensino e Pesquisa e do Comitê de Ética em Pesquisa da Escola de Enfermagem da USP. Além disso, os participantes do estudo foram esclarecidos acerca dos objetivos da pesquisa e receberam o Termo de Consentimento Livre e Esclarecido, que versou sobre os aspectos éticos em pesquisas envolvendo seres humanos.

O instrumento de coleta de dados foi constituído por questões norteadoras a respeito da escolha profissional dos colaboradores, suas expectativas, motivações em relação à profissão da enfermagem, facilidades e dificuldades na escolha e no exercício profissional.

A exploração do material consistiu essencialmente de operações de codificação, pois de acordo com Bardin, nessa etapa são realizados os reajustamentos necessários ao processo de organização da análise, sendo feita a denominação das categorias (BARDIN, 1977).

Na fase da interpretação dos dados obtidos, percorremos a análise do conteúdo com a discussão das categorias que foram sendo construídas, fazendo uma interligação dos dados encontrados com o referencial teórico existente sobre os assun- tos, transformando-os em conteúdos significativos e válidos. Foram desveladas as seguintes tematizações: fatores que propiciaram a escolha e o exercício profissional, dificuldades enfrentadas durante a atuação profissional.

\section{RESULTADOS E DISCUSSÃO}

A sistematização dos achados possibilitou a construção de unidades de significados seguintes concernentes ao objeto da presente investigação:

\section{Fatores que propiciaram a escolha e o exercício profissional}

Ao escolherem a profissão de enfermagem, os sujeitos participantes do presente estudo também revelaram algumas facilidades no exercício da mesma, sendo um importante fator de estímulo para o cumprimento de suas atividades profissionais, conforme podemos perceber nos discursos.

$\mathrm{O}$ fato de trabalhar em mais de um emprego, ter várias áreas de atuação profissional e ter autonomia profissional foram facilidades pontuadas pelos colaboradores.

"... a enfermeira tem a opção de trabalhar 12 por 36, coisa que eu já fiz mudando de emprego, assim, de levar..." (C.T.K.)

"Tem muitos lugares que uma enfermeira pode trabalhar, e eu acho que o enfermeiro dedicou e se empenhou na escola e que continua estudando, continua se atualizando ele... ele tem muito a dar, não é? Ele tem muito a contribuir para a sociedade, pra situação da escola, pra uma empresa, não é? Que tem enfermeiros do trabalho, não é? Eu vejo muito a importância do enfermeiro para o hospital". (H.S.R)

"Tem que estudar! Pra ser respeitada, tem que estudar, não é?” (I.F.R)

"Graças a licenciatura eu consegui entrar numa vaga caracterizada, pra trabalhar no desenvolvimento de recursos humanos". (H.M.F)

Nesse sentido, estudo realizado sobre facilidades para a formação e atualização de enfermeiros destacou os seguintes fatores: disponibilidade de recursos para a atuação profissional, oferta de cursos de atualização ou aprimoramento na área da enfermagem (inclusive aos finais de semana) e ajuda financeira para consecução dos cursos mencionados. Tais facilidades contribuíram para a 
satisfação e realização do profissional na carreira de enfermagem (SOUZA, ALENCASTRE, SAEKI, 2000).

Em estudo com graduados e docentes da Escola de Enfermagem da Universidade de São Paulo foram identificados outros elementos facilitadores da práxis profissional: estrutura organizacional e desenvolvimento pessoal (DOMENICO, IDE, 2006).

Quanto à estrutura organizacional, as autoras pontuaram a importância da qualidade e quantidade dos recursos humanos, materiais e físicos, a fim de assegurar o cumprimento das tarefas diárias e otimização do tempo. Elas ressaltaram, ainda, que os graduados verbalizaram que, em unidades críticas, a proximidade da equipe médica lhes garantia uma maior tranquilidade, o que revelou uma responsabilidade compartilhada no tocante ao cuidado e o gerenciamento do cuidado. Quanto ao desenvolvimento pessoal, foram elencadas situações que facilitaram a práxis profissional, a importância da competência e o desenvolvimento da comunicação e do relacionamento interpessoais.

Alguns depoimentos revelaram facilidades no exercício da profissão relativas à autonomia profissional e às condições de trabalho. $\mathrm{O}$ discurso que segue retrata essa experiência:

“Ah! Em tal hospital sei lá o que particular, as enfermeiras tem boa condições de trabalho, elas podem ter todo o material necessário, tem todo o tempo de ficar com aquele paciente, de fazer uma consulta...”. (H.S.R)

Outro sujeito participante ressaltou a satisfação pessoal com a conquista de autonomia profissional, como podemos observar na fala seguinte:

"Eu acho que a Enfermagem já galgou algumas facilidades em termos de autonomia. Tem autonomia pra certas coisas, pra certas decisões... E eu sempre achei que ela era muito dependente nas decisões que ela tinha que tomar, sempre dependendo do aval de alguém." (S.N.S.)

Em relação à autonomia profissional, autores afirmam que esta se refere à autodeterminação, no sentido do profissional ser independente ou tomar decisões por conta, de autogovernar-se. Nessa direção, há estudos que enfatizam que a autonomia profissional é a capacidade de controlar por si mesmo os aspectos técnicos de seu próprio trabal- ho (SADALA, 1996; MACHADO, 1995).

Nesse sentido, cabe ressaltar que o enfermeiro se sente mais satisfeito com os aspectos intrínsecos de seu trabalho e quando ele é valorizado nos seguintes elementos: reconhecimento, responsabilidade e autonomia (RODRIGUES, SCATENA, LABATE, 1997).

Alguns autores questionam a falta de autonomia do enfermeiro no cumprimento de suas atividades profissionais e pontuam que este profissional não se sentirá satisfeito enquanto não puder praticar sua profissão com conhecimentos e julgamentos independentes para benefício dos pacientes (KELLY, 1999).

Nos fragmentos abaixo, os sujeitos da presente pesquisa relataram experiências que revelam facilidades no exercício da enfermagem:

"A Enfermagem é uma profissão holística, que pode atuar em áreas que a gente nem imaginava. Já existe até Enfermagem espacial hoje em dia. Nós estamos descobrindo novas opções a cada dia." (A.C.S)

"...eu acho que hoje em dia, ainda mais, é uma profissão que tem muito futuro, ela tem um campo muito grande, eu acho até que hoje mais, do que, por exemplo, quando me formei, hoje existe uma série de outras vertentes que você pode se enveredar, que foram aparecendo ao longo do tempo..." (E.S.)

A existência e a atuação de entidades de classe, como o Conselho Regional de Enfermagem, constituíram-se em elemento facilitador para o exercício da enfermagem, de acordo com os seguintes discursos:

"Além disso, nós temos um Conselho, coisa que algumas profissões da área da saúde ainda não têm, nós temos o nosso COREN, que foi luta de vários enfermeiros do passado pra gente chegar aí, nós temos que agradecer a eles, temos a Associação Brasileira de Enfermagem e temos o nosso sindicato." (A. C. S)".

A atuação do profissional encontra-se regulamentada na própria legislação de criação do Conselho Federal de Enfermagem e dos Conselhos Regionais de Enfermagem (BRASIL, 2001), pois essa legislação especifica as atribuições e responsabilidades desses órgãos na regulamentação do exercício da enfermagem, no Brasil. 
Os colaboradores pontuaram que dificuldades podem provocar desânimo e propiciar distanciamento das expectativas do profissional em relação à escolha profissional e gerando sentimentos de decepção e frustração.

\section{Dificuldades enfrentadas durante a atuação profissional}

Nos depoimentos seguintes pontuaram-se dificuldades que foram vivenciadas por estes colaboradores no tocante à própria atuação profissional:

“... uma coisa é você juntar uma turma de enfermeiras e oferecer o serviço e vocês imporem as condições, outra coisa é hospitais, clínicas, laboratórios impor pra vocês se associarem a cooperativas ou terceirizar o serviço, só lucra o empregador." (C.T.K.)

"E... mas em nenhum momento pensei em desistir da enfermagem, eu sempre, apesar das dificuldades, principalmente relacionada a conteúdo e segurança dos professores, tinham muitos professores que eram... que não tinham experiência profissional. Eles se formaram e em seguida foram professores e isto me irritava muito, não é? Por que a gente via que na prática eles não passavam uma experiência prática, queria mesmo a vivência do enfermeiro, eu não queria teoria, teoria a gente vê em livros, não é? Então essa foi uma... o principal problema que eu ...eu enfrentei naquela época foi esse, não é? E... eu pensava eu nunca vou ser uma enfermeira" (H.S.R)

"A enfermeira, ela tem uma série de dificuldades perante outros profissionais, principalmente o médico, que a gente tem atuando na área. Na realidade, eu acho que até hoje, nós temos como se o paciente fosse do médico, na realidade é da equipe. Eu acho que há um bom tempo que a gente vem tido as equipes multiprofissionais que são muito importantes, ninguém é dono do paciente. Existe sim, uma equipe, que cada um com a sua função é...desempenhar o seu papel no cuidado do paciente. É...eu sempre fui bastante espirituosa e bastante crítica, é...aprendi muito.” (I.F.R)

Nessa perspectiva, estudo realizado acerca da motivação para a evasão de enfermeiros da profissão concluiu que o excessivo contingente de profissionais de enfermagem representa importante fator no fenômeno investigado, sobretudo em determinadas regiões do país, como é o caso da região sudeste, especialmente no Município de São Paulo13. Ademais, os autores mencionados destacam as carências ou falta de remuneração adequa$\mathrm{da}$, falta de prestígio ou reconhecimento social, falta de autonomia para desenvolver o seu trabalho, falta de espírito de equipe/união da classe, deficientes condições de trabalho (infra-estrutura de pessoal e recursos materiais), carência de perspectivas futuras, bem como falta de estímulos ao aperfeiçoamento/crescimento, dentre outros aspectos.

As dificuldades elencadas decorreram, muitas vezes, da organização social do trabalho do enfermeiro e extrapolam sua vontade e os interesses políticos da categoria profissional13.

Algumas falas dos participantes expressaram sentimentos vivenciados por eles no que tange às dificuldades ao longo de suas trajetórias profissionais, destacando-se os problemas relativos à remuneração, ao prestígio / reconhecimento, às condições e horários de trabalho, além do estresse.

"Olha, ainda na época, o salário não era tão ruim como é agora, né.” (C.T.K.)

Quanto ao prestígio e reconhecimento social, alguns sujeitos manifestaram em suas falas como perceberam esse sentimento e lidaram com ele:

"Era uma coisa de a gente lutar de unhas e dentes, porque não era uma profissão reconhecida. (...) Quando você ia para o mercado de trabalho, pra você mostrar o seu valor como profissional, e tirar aquele estigma de que enfermeira era ajudante de médico, era muito dificil". (M.C.P.S.)

"E é uma pena, porque, não é?... é uma profissão... mas, assim, saúde e educação são as áreas que o profissional tem que investir muito e sempre $e$ é pouco reconhecido, é um retorno... não tem reconhecimento, por conta disso não é valorizado, o profissional não é valorizado, porque o que, o que é valorizado é o que reverte em dinheiro". (C.T.K.)

"No exercício de minha profissão, eu tive, assim, veja bem, você nunca, nunca, espere reconhecimento de nada, porque se não você vai viver frustrada”. (E.S)

Em relação às condições de trabalho, destacase a seguinte fala:

"Às vezes a gente não tem nem tempo, a gente não faz uma consulta, faz uma orientação, faz 
alguma outra coisa para o paciente, mas não consulta não é? Ou não tem estrutura, não tem uma sala, não tem ... às vezes o aparelho de pressão está quebrado e não tem outro e assim por diante." (H.S.R.)

Outra dificuldade na atuação do enfermeiro era concernente à jornada de trabalho, conforme ressalta trecho do discurso seguinte:

“... você não tem... é... sábado, domingo $e$ feriado...”(C.T.K.)

Já em relação às situações de estresse, dois sujeitos revelaram que:

“(...) Tinha muita coisa para fazer, e a gente trabalha dando murro em ponta de faca, não é?!" (M.C.P.S.)

“(...) é uma vida dura, principalmente para quem trabalha na área hospitalar, a questão de horário, lidar com o paciente. (...) É um trabalho estressante, você fica muito tempo em pé..." (S.N.S.)

Estudo realizado sobre a satisfação ou insatisfação dos enfermeiros com o que fazem destacou os seguintes aspectos como mais importante: a remuneração incompatível com as responsabilidades que assumem e o desgaste pelo exercício de suas funções, além do sentimento de desvalorização do valor do seu trabalho. Essas dificuldades também foram citadas nos relatos dos participantes da presente investigação, além da jornada de trabalho, muitas vezes, extenuante, além da falta de tempo para a realização de outras atividades, da falta de recursos para o adequado desempenho das atividades profissionais, dos altos níveis de estresse e de dificuldades para lidar com os pacientes (SECAF, RODRIGUES, 1998).

A falta de vagas no mercado de trabalho e a dificuldade para o desempenho de atividades específicas do enfermeiro expressas em lei foram também lembrados como elementos que dificultaram sua prática e reconhecimento. Esses problemas foram apontados nas seguintes frases:

"Hoje, eu tenho alunos excelentes que estão ficando de seis meses a um ano desempregados. $O$ mercado já não está fácil. Você quer ter emprego? Vá pra fora de São Paulo (...)” (A. C. S.)

"Por outro lado, existe muita gente entrando no nosso campo. Muitos profissionais da área da saúde não estão muito bem localizados (...). Então, essa invasão no objeto da Enfermagem, eu tenho visto como perigosa." (A. C. S.)

\section{CONCLUSÃO}

Os estudos históricos podem corroborar para a compreensão da trajetória profissional, além da memória e da identidade da profissão da enfermagem, bem como as representações e significados que têm sido socialmente atribuídos ao enfermeiro e ao que ele faz. Assim, a história da enfermagem permite-nos desvelar transformações da profissão e compreender movimentos da construção / desconstrução e reconstrução do passado, na perspectiva do resgate e da preservação da memória coletiva1.

A noção de que a história é algo velho, pronto e acabado está sendo superada por uma visão mais dinâmica do seu mister na tecitura do passado e das ações humanas, pois o próprio ser humano faz a história como agente de transformações. Ademais, a história pode ser vista como um instrumento de legitimação, sendo, portanto, importante conhecêla e analisar criticamente como se constrói a representação social de um determinado grupo social, (como é o caso da enfermagem), desvelando-se significados atribuídos à atuação e papel social desses agentes.

Os resultados dessa investigação contribuíram para o resgate da memória da história da Escola de Enfermagem da Universidade de São Paulo, identificando fatores que facilitaram ou dificultaram o processo da formação e atuação profissionais os desafios que os colaboradores vivenciaram em suas trajetórias acadêmica e profissional.

Os fatores facilitadores no exercício profissional citados pelos sujeitos desta pesquisa estão relacionados aos cenários de prática profissional, à promoção da educação continuada, à existência e à atuação das entidades de classe em prol das prerrogativas de regulamentação do exercício dos profissionais dessa área.

Quanto às dificuldades vivenciadas pelos sujeitos da pesquisa, destacaram-se os problemas relativos à remuneração, ao prestígio/reconhecimento, às condições e horários de trabalho, estresse, realidade em campo muito diferente dos estágios proporcionados durante a formação e falta de trabalho em equipe. 
Entendemos que novos horizontes acerca desta temática poderão ser explorados, a fim de descortinar a identidade e memória coletivas das instituições de ensino em enfermagem, a partir das reminiscências invocadas pelos profissionais egressos da profissão. Nessa direção, as dificuldades e facilidades enfrentadas pelos egressos da enfermagem encontram-se pontuadas, como possibilidades para avançar na construção do passado e da identidade profissional da enfermagem.

Ao ampliarmos o conhecimento sobre as dificuldades e facilidades dos egressos da Escola de Enfermagem da USP, percebemos a importância da memória histórica dos sujeitos que escolheram essa profissão, as transformações e conquistas importantes por eles vivenciadas.

\section{REFERÊNCIAS}

- BARDIN, L. (1977) Análise de conteúdo. Lisboa: Edições 70.

- BRASIL. (2001) Lei no 5.905, 12 de julho de 1973. Dispõe sobre a criação dos Conselhos Federal e Regionais de Enfermagem e dá outras providências. Conselho Regional de Enfermagem do Estado de São Paulo. Documentos básicos de enfermagem: enfermeiros, técnicos e auxiliares. Conselho Regional de Enfermagem do Estado de São Paulo.

- CARVAlHO, AC. (1980) Resumo histórico - 1942 -1980. Rev Esc Enferm USP; 14 (supl. P. 1-271).
- DOMENICO, EBL; IDE, CAC. (2006) As competências do graduado em enfermagem: percepções de enfermeiros e docentes. Acta Paul Enferm; 19(4):394-401.

- KELLY BO. (1999) Satisfied with your job? Nurs. Manage, Ohio; 160( 26): 56-8.

- MACHADO MH. (1995) Sociologia das Profissões: Uma Contribuição ao Debate Teórico. In: Machado MH. Profissões De Saúde: Uma Abordagem Sociológica. Rio D e Janeiro; Fiocruz

- OGUISSO, T. (2007) Trajetória Histórica e Legal da Enfermagem. São Paulo: Manole.

- RODRIGUES ARR, SCATENA MCM, LABATE RCO. (1997) O aluno ingressante de enfermagem - abordagem compreensiva. Revista de enfermagem UERJ. Rio de Janeiro; 5 (1).

- SADALA, MLA. (1996) Autonomia/mutualidade na assistência de enfermagem. Rev.Latino-am.enfermagem; 4 (1): 11117.

- SAUTHIER, J; CARVAlHO, V. (1999) A Missão Parsons: documentos históricos da EEAN / UFRJ - 1922 a 1931. Rio de Janeiro: Anna Nery/UFRJ.

- SAUTHIER, J; BARREIRA, IA. (1999) As enfermeiras norteamericanas e o ensino de enfermagem na Capital do Brasil: 1921 - 1931. Rio de Janeiro: Anna Nery/UFRJ.

- SECAF, V; RODRIGUES, A. (1998) Enfermeiros que deixaram de exercer a enfermagem: Por que? Rev.latinoam. Enfermagem; 6(2): 5-11

- SOUZA, MCBM; ALENCASTRE, MB; SAEKI, T. (2000) Enfermeiros assistenciais das instituições psiquiátricas de Ribeirão Preto: caracterização, formação e atuação. Rev.latino-am.enfermagem; 8(5): 71-80.

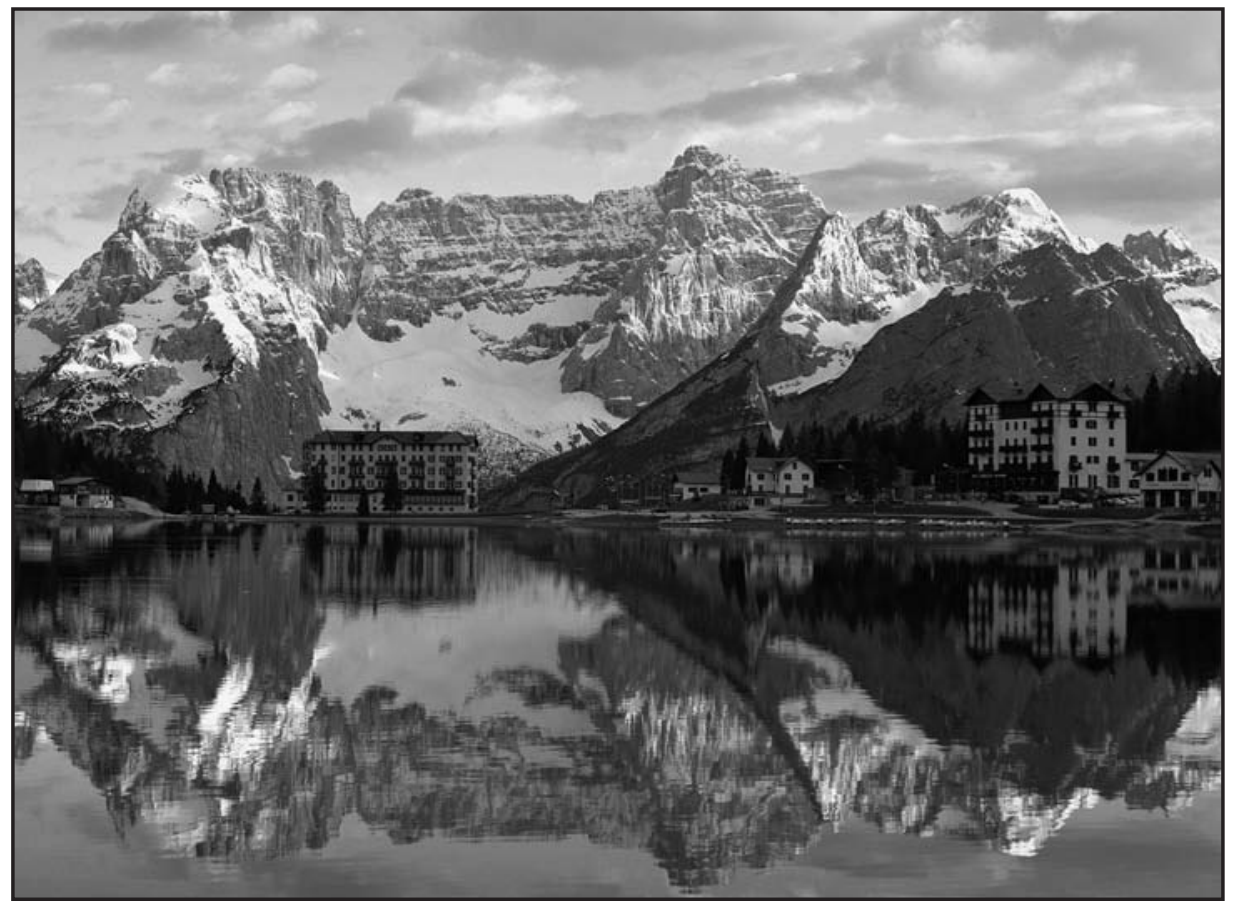

